Jurnal Sistem Informasi (Journal of Information Systems). 2/13 (2017), 78-89

DOI: http://dx.doi.org/10.21609/jsi.v13i2.555

\title{
ANALISIS DAN PERANCANGAN INTERAKSI CHATBOT REMINDER DENGAN USER- CENTERED DESIGN
}

\author{
Ahmad Alim Akhsan ${ }^{1}$ dan Faizah ${ }^{2}$ \\ ${ }^{1,2}$ Departemen Ilmu Komputer dan Elektronika, Fakultas Matematika dan Ilmu Pengetahuan Alam, \\ Universitas Gadjah Mada, Bulaksumur, Yogyakarta, 55281, Indonesia \\ E-mail: 19alim.akhsan@gmail.com, ${ }^{2}$ faizah@ugm.ac.id
}

\begin{abstract}
The presence of technology that is not prepared to face user interaction could worsen the user experience. There are still many chatbot reminders that cannot fulfill the users' expectations. Usercentered design approach can help to overcome the problems associated with the user. In this research, Google Design Sprint as a user-centered design approach was used in the analysis until testing phase. Interaction was the main problem to be analyzed and was expected to improve the user experience. Design recommendation and prototype for a new chatbot refers to the result of usability testing of four previous chatbots. Testing was done by doing usability testing of a new chatbot. A total of five different participants were used each chatbot during usability testing. The results of usability testing of the new chatbot prototype were compared to the previous chatbots. The result was the new chatbot has a SUS (System Usability Scale) score of 70.5. The score increases up to 18.4 from previous chatbots on average. Based on data obtained from usability testing and SUS score, it was concluded that interaction and appropriate selection of interfaces could improve the user experience of chatbot.
\end{abstract}

Keywords: interaction, chatbot, user-centered design, user experience

\begin{abstract}
Abstrak
Keberadaan teknologi yang tidak dipersiapkan untuk menghadapi interaksi dengan pengguna akan membuat user experience menjadi buruk. Masih banyak ditemukan chatbot reminder yang tidak dapat memenuhi harapan pengguna. Pendekatan user-centered design dapat membantu dalam mengatasi masalah yang berhubungan dengan pengguna. Pada penelitian ini digunakan metode Google Design Sprint sebagai pendekatan user-centered design dalam tahapan analisis hingga pengujian. Interaksi merupakan masalah utama yang dianalisis dan diharapkan dapat meningkatkan user experience. Rekomendasi rancangan dan prototype chatbot baru mengacu pada hasil usability testing empat chatbot terpilih. Pengujian dilakukan dengan melakukan usability testing pada prototype chatbot baru. Sebanyak lima partisipan yang berbeda digunakan setiap chatbot pada saat usability testing. Hasil usability testing chatbot baru kemudian dibandingkan dengan chatbot lama. Diperoleh skor SUS (System Usability Scale) chatbot baru sebesar 70,5. Skor tersebut meningkat sebanyak 18,4 secara ratarata dari chatbot lama. Berdasarkan data yang diperoleh saat usability testing dan skor SUS dapat diambil kesimpulan bahwa interaksi dan pemilihan antarmuka yang tepat dapat meningkatkan user experience pada chatbot.
\end{abstract}

Kata Kunci: interaksi, chatbot, user-centered design, user experience

\section{Latar Belakang}

Chatbot merupakan sebuah program komputer yang dapat menjalankan intelligent conversation dengan pengguna melalui media suara ataupun teks, sering kali dilakukan dengan percakapan yang singkat [1]. Chatbot bekerja dengan mengartikan pesan yang diberikan oleh pengguna, kemudian memproses maksud dari pesan tersebut, selanjutnya menentukan dan mengeksekusi apa yang perlu chatbot lakukan berdasarkan perintah dari pengguna, dan terakhir menyampaikan hasil dari eksekusi program kepada pengguna [2].
Pada tahun 2015, Facebook mulai mengizinkan para pengembang untuk membuat sebuah chatbot pada platform Messenger yaitu aplikasi kirim pesan buatan Facebook. Selain itu, Messenger menyediakan tombol dan pesan bagi chatbot dengan antarmuka yang kaya informasi. Hal tersebut dapat membantu memudahkan interaksi yang dilakukan pengguna dengan chatbot, sekaligus membuka peluang bagi para pengembang untuk merancang interaksi dan antarmuka pada chatbot. Setiap chatbot yang ada pada Messenger difokuskan pada satu fitur tertentu. Salah satu fitur yang penting untuk digunakan dalam kehidupan sehari-hari adalah me- 


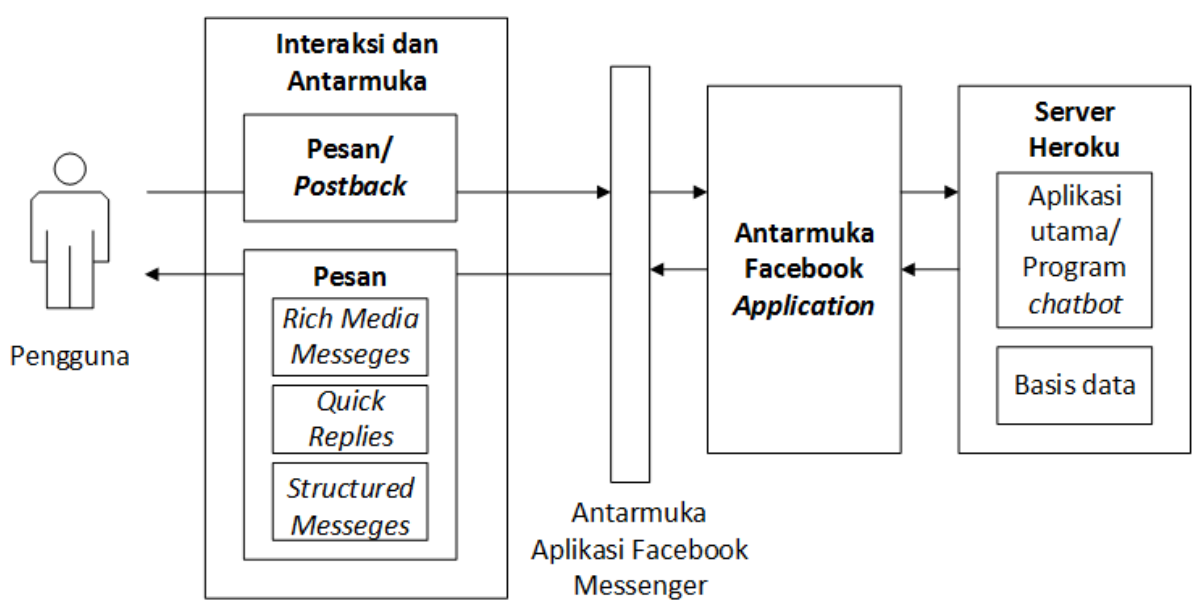

Gambar 1. Lingkup permasalahan

ngingat suatu pekerjaan. Namun, masih banyak orang yang mengabaikan untuk membuat dan mengorganisir pekerjaan ke dalam sebuah reminder.

Allen [3] menjelaskan bahwa reminder merupakan sesuatu ataupun pekerjaan yang diubah menjadi sekumpulan kertas atau layanan web yang kemudian kita percayakan untuk menyimpan hal tersebut atau bisa disebut sebagai trusted system. Adanya chatbot reminder diharapkan dapat membantu mengingatkan pekerjaan dalam kehidupan sehari-hari. Akan tetapi, masih banyak pengguna yang tidak menyukai chatbot karena kesulitan dalam berinteraksi dengan chatbot. Padahal interaksi yang dirancang untuk meningkatkan pengalaman pengguna menjadi hal penting dalam merancang sebuah chatbot agar pengguna tidak merasa kesulitan.

Beberapa penelitian sebelumnya telah mengkaji bagaimana performa chatbot $[1,4]$. Kuligowska [4] membandingkan beberapa chatbot yang ada untuk mengetahui tingkat performanya. Namun, belum mengikutsertakan aspek dari user experience. Salah satu cara yang dapat dilakukan untuk memperdalam aspek tersebut adalah dengan menggunakan pendeketan user-centered design dimana pengguna dilibatkan pada salah satu atau lebih [5]. Penelitian ini tidak terlepas dari memanfaatkan penelitian yang sudah ada. Hasil dari penelitan Hill [6] dijadikan patokan bagaimana bahasa yang perlu digunakan dalam perancangan chatbot. Serta diacu beberapa evaluasi yang perlu diperhatikan dari hasil penelitian Hung [7] dalam analisis dan perancangan chatbot baru seperti ease of usage, clarity, naturalness, friendliness, robustness regarding misunderstandings, dan willingness to use system again.

Pada penelitian ini, akan dilakukan analisis dan perancangan interaksi chatbot reminder deng- an menggunakan pendekatan user-centred design yang didasarkan pada hasil evoluasi empat chatbot lain yang telah ada. Pada bab selanjutnya akan dijelaskan tahapan metode yang dilakukan serta hasil pengujian pada beberapa skenario. Kemudian di bagian akhir akan diberikan kesimpulan sekaligus rekomendasi untuk penelitian selanjutnya.

\section{Metode}

Permasalahan utama yang akan diselesaikan pada penelitian ini adalah bagaimana mencari solusi untuk meningkatkan pengalaman pengguna dengan merancang interaksi dan antarmuka antara pengguna dengan chatbot. Lingkup permasalahan yang dibahas merupakan interaksi dan antarmuka berbalas pesan antara pengguna dengan chatbot dan secara singkat digambarkan pada Gambar 1.

Untuk menyelesaikan permasalahan tersebut digunakan metode user-centered design pada tahap awal dan akhir analisis. User-centered design (UCD) adalah sebuah istilah umum yang menjelaskan proses desain dimana pengguna terlibat dalam pembentukan desain [5]. Banyak yang menggambarkan bagaimana pengguna terlibat dalam proses UCD, tetapi konsep yang terpenting adalah pengguna dilibatkan dalam satu hal atau lebih. Sebagai contoh, beberapa jenis UCD menanyakan mengenai kebutuhan dan melibatkan pengguna pada waktu tertentu selama proses desain berjalan. Di sisi lain, pengguna dapat terlibat lebih dalam selama proses desain.

Diperlukan ketelitian saat melibatkan pengguna dalam proses desain, mengenai siapa saja dan bagaimana pengguna terlibat. Dapat dilihat pada Tabel 1 bagaimana pengguna terlibat dalam sebuah proses desain meliputi teknik yang digunakan, tujuan, serta berada pada tahapan desain apa teknik 
TABEL 1

Melibatkan Pengguna Dalam Proses Desain [5] Dengan Sedikit Perubahan

\begin{tabular}{|c|c|c|}
\hline Teknik yang Digunakan & Tujuan & $\begin{array}{l}\text { Tahapan dari Siklus } \\
\text { Desain/Perancangan }\end{array}$ \\
\hline $\begin{array}{l}\text { Serangkaian wawancara } \\
\text { dan kuisioner }\end{array}$ & $\begin{array}{l}\text { Mengumpulkan data yang berhubungan dengan serangkaian } \\
\text { tindakan yang dilakukan pada produk }\end{array}$ & Tahap awal dalam siklus desain \\
\hline Usability testing & $\begin{array}{l}\text { Mengumpulkan data kuantitatif yang berhubungan dengan } \\
\text { kriteria usability }\end{array}$ & Tahap akhir dalam siklus desain \\
\hline Wawancara dan kuisioner & $\begin{array}{l}\text { Mengumpulkan data kuantitatif yang berhubungan dengan } \\
\text { kepuasan pengguna terhadap produk }\end{array}$ & Tahap akhir dalam siklus desain \\
\hline
\end{tabular}

tersebut digunakan [5]. Teknik yang dijelaskan pada tabel adalah teknik yang digunakan pada penelitian ini. Tahapan penelitian ini mengacu pada enam tahapan yang digunakan untuk merancang dan me-ngevaluasi sebuah desain [8] dan secara terperinci di-gambarkan pada Gambar 2.

\section{Tahap 1 - Understand}

Tahap understand merupakan tahap pertama yang bertujuan untuk mencari tahu permasalahan pada chatbot yang sudah ada di pasaran. Pengumpulan data permasalahan dilakukan dengan usability testing serta analisis terhadap rancangan chatbot lama yang terpilih. Untuk menjalankan usability testing, diperlukan persiapan dengan memilih chatbot dan mencari partisipan, merancang skenario, menyusun sistem penilaian, dan menentukan cara pengumpulan data usability testing.

Pencarian chatbot dilakukan melalui beberapa situs, yaitu botlist.co, botpages.com, dan melalui fitur pencarian Messenger. Dalam penelitian ini, tidak semua chatbot digunakan sehingga perlu dilakukan pemilihan seperti yang dilakukan Kuligowska [4]. Kategori penilaian dalam pemilihan chatbot dibagi menjadi dua hal. Pertama, bagaimana kemampuan chatbot dalam memahami konteks yang dikirimkan oleh partisipan. Kedua, kemampuan chatbot yang berhubungan dengan fungsi utama reminder. Dari penilaian dua kategori tersebut, diperoleh empat chatbot yang digunakan pada penelitian ini, yang selanjutnya disebut dengan chatbot lama. Nama chatbot terpilih dapat dilihat pada Lampiran Tabel I.

Persiapan usability testing dilakukan dengan mempersiapkan sistim penilaian yaitu SUS, kuesioner, dan membuat skenario usability testing. System Usability Scale (SUS) merupakan pengukuran usability yang sederhana. SUS menyediakan sepuluh pernyataan berbentuk kuesioner dalam pengukuran yang dapat memberikan gambaran secara luas mengenai penilaian usability [9]. SUS menggunakan skala Likert yang terbagi menjadi lima, yaitu 1: sangat tidak setuju, 2: tidak setuju, 3: netral, 4: setuju, dan 5: sangat setuju.

Pada Lampiran Tabel II dipaparkan isi dari kuesioner SUS yang sudah diterjemahkan ke dalam Bahasa Indonesia dan disesuaikan dengan peneliti- an ini. Dapat dilihat pernyataan yang terdapat pada kuesioner SUS sudah mencakup berbagai aspek dari usability suatu sistem.

Usability testing merupakan salah satu proses desain dalam UCD yang dilakukan untuk mengetahui apakah sebuah produk sesuai dengan kriteria usability dengan melibatkan pengguna dalam pengujian. Pada Lampiran Tabel III tertera skenario pekerjaan yang digunakan pada penelitian ini. Skenario ditentukan setelah dilakukan percobaan pada beberapa pengguna di luar partisipan, kemudian dipilih skenario yang dinyatakan cocok dan dapat dijalankan pada seluruh chatbot.

Setelah rancangan skenario pekerjaan dan kuesioner SUS dianggap layak untuk digunakan pada usability testing, selanjutnya adalah pelaksanaan usability testing. Pelaksanaan usability testing dibagi ke dalam tiga tahapan: 1) Tahap pertama yaitu partisipan mengisi kuesioner yang meliputi data pribadi, data penggunaan aplikasi kirim pesan, data perilaku menggunakan internet, data perilaku dan tanggapan mengenai reminder. Data tersebut digunakan untuk menggambarkan demografi pengguna dengan menggunakan sampel data dari lima partisipan pada masing-masing chatbot lama dan baru; 2) Tahap kedua adalah menjalankan skenario. Pada tahap ini partisipan diminta untuk mengerjakan skenario yang telah dirancang dengan menggunakan chatbot pada perangkat smartphone; 3) Di tahap terakhir dilakukan pengisian kuesioner SUS, saran, dan tanggapan partisipan terhadap chatbot yang digunakan.

Pelaksanaan usability testing dibagi menjadi tiga tahapan. Tahap pertama, yaitu partisipan mengisi kuesioner yang meliputi data pribadi untuk menggambarkan demografi pengguna. Tahap kedua adalah menjalankan skenario usability testing menggunakan chatbot lama dengan merekamnya pada perangkat smartphone. Tahap terakhir adalah pengisian kuesioner SUS, dan tanggapan partisipan terhadap chatbot yang digunakan.

Setelah usability testing dilakukan, diperoleh data berupa rekaman partisipan dalam menjalankan skenario. Data yang didapatkan selanjutnya dianalisis sehingga diperoleh gambaran permasalahan dan kebutuhan dari chatbot. Selain data usability testing, dilakukan juga analisis terhadap rancangan, antara lain use case diagram, activity diagram, 


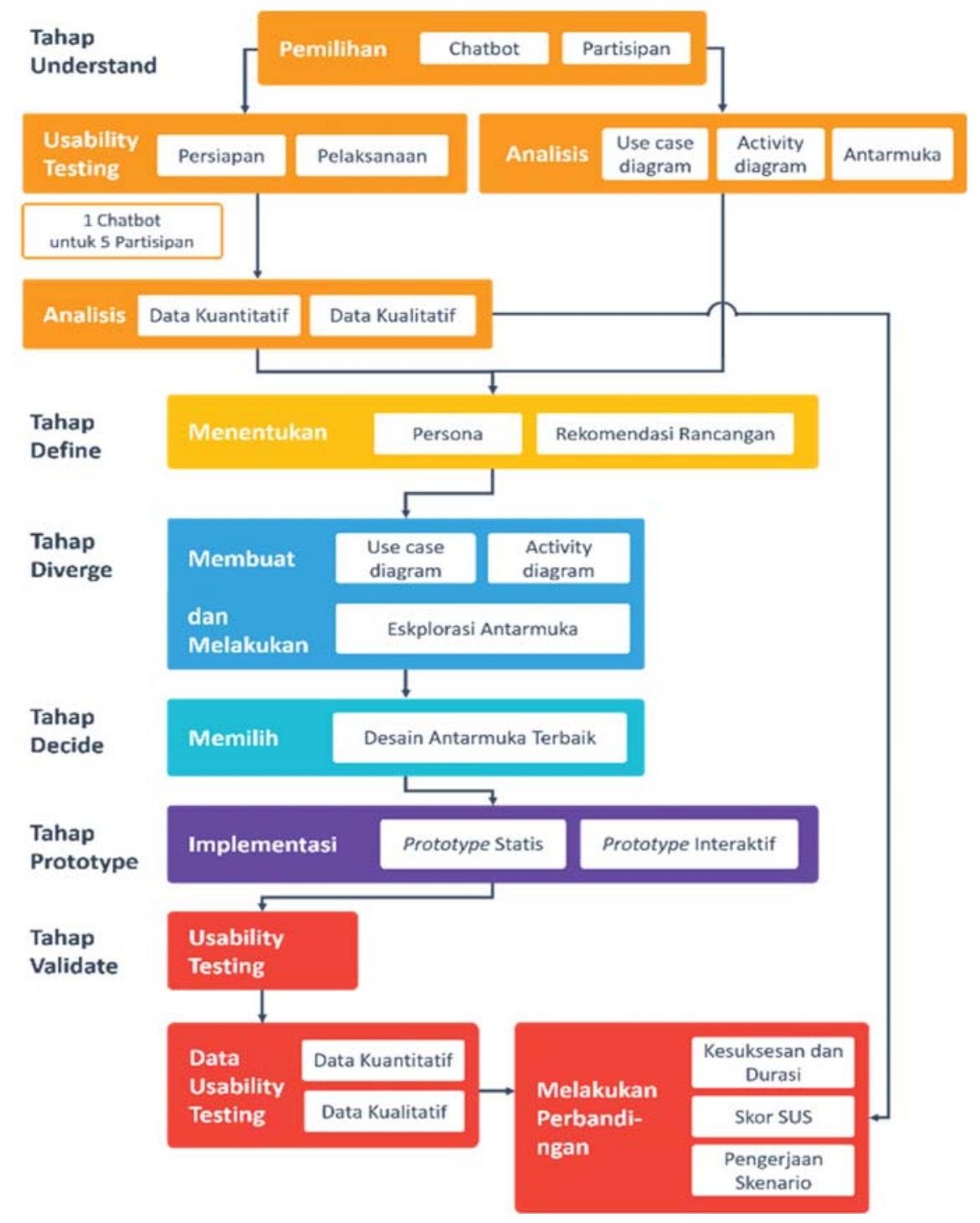

Gambar 2. Tahapan penelitian

dan antarmuka. Hasil analisis dari tahap ini akan digunakan pada tahap selanjutnya, yaitu tahap define.

Analisis data kuantitatif dan data kualitatif didapatkan melalui data yang dikumpulkan saat melakukan usability testing. Analisis pada data kuantitatif dibagi menjadi tiga bagian, yaitu analisis untuk kesuksesan pengerjaan skenario, durasi pengerjaan skenario, dan perhitungan kuesioner SUS. Sedangkan data kualitatif merupakan data perilaku dan tanggapan partisipan dalam pengerjaan skenario pada usability testing, beserta kuesioner tanggapan dan saran. Pada Lampiran Gambar I diperlihatkan contoh antarmuka dua chatbot lama yaitu BigBot dan ReMind ketika menghapus reminder.

\section{Tahap 2 - Define}

Pekerjaan utama yang dilakukan pada tahap define adalah menentukan strategi yang akan dilakukan setelah melihat permasalahan dari tahap understand. Strategi dimulai dengan menentukan persona sebagai target pengguna dan menentukan rekomendasi rancangan pada chatbot baru. Persona yang digunakan sebagai target pengguna terdiri dari tiga macam persona yang diperoleh dari hasil usability testing. Ketiga persona tersebut memiliki tujuan yang berbeda dalam menggunaan reminder, antara lain: 1) Pengguna yang menyukai setiap kegiatan terorganisir. Biasanya pengguna yang seperti ini menganggap bahwa membuat dan menggunakan reminder adalah hal penting dan telah menjadi ke- 


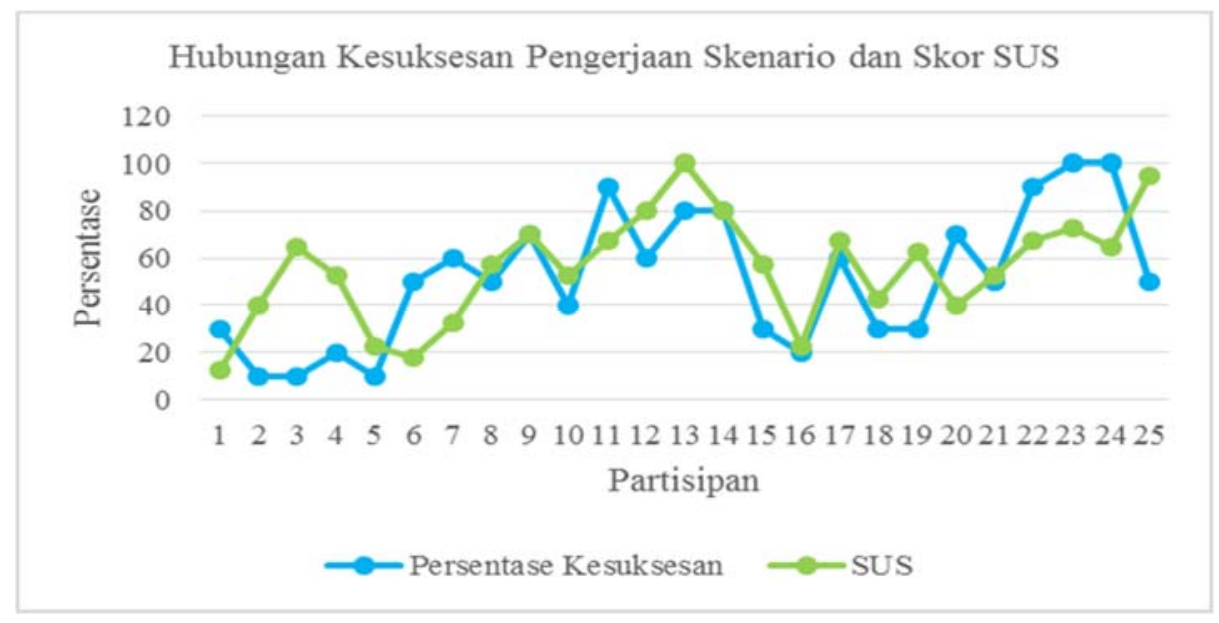

Gambar 3. Hubungan Kesuksesan Pengerjaan Skenario dan Skor SUS

butuhan; 2) Pengguna yang membutuhkan reminder pada kegiatan tertentu; 3) Pengguna yang berada pada situasi diharuskan menggunakan reminder.

Secara garis besar, rekomendasi disorot dari BigBot, ReMind dan Reminders. Reminders memiliki pengalaman yang baik dengan partisipan dikarenakan memiliki kemampuan dalam mengatasi interaksi penambahan reminder yang bervariasi dan penyajian pesan yang lebih mudah dipahami. Di sisi lain, BigBot tidak memiliki pengalaman pengguna yang baik seperti Reminders, tetapi kemampuan BigBot dalam mengatasi masukan berupa teks menjadi poin menarik untuk rekomendasi. Adapun ReMind berperan dalam membuka ide untuk mempersingkat langkah aktivitas menghapus reminder sehingga muncul aktivitas undo pada chatbot baru.

Rekomendasi aktivitas menambah reminder diadopsi dari Reminders yang dapat mengatasi varian interaksi. Begitu pula dengan daftar reminder yang disajikan secara sederhana oleh Reminders. Sebaliknya, direkomendasikan mengadopsi kemampuan BigBot dengan melakukan modifikasi dalam mengatasi masukan berupa teks pada aktivitas menghapus, menjadwal ulang, menunda, dan menandai selesai.

\section{Tahap 3 - Diverge}

Diverge merupakan tahap untuk mendapatkan ide sebanyak mungkin dalam merancang sebuah produk dengan mengacu dari hasil analisis pada tahap define. Eksplorasi antarmuka yang dihasilkan pada tahap ini berbentuk rancangan low-fidelity dalam media kertas. Pada tahap ini, dirancang use case diagram dan activity diagram chatbot baru. Selain itu, dilakukan juga eksplorasi terhadap antarmuka yang bertujuan untuk mendapatkan rancangan sebanyak mungkin.

\section{Tahap 4 - Decide}

Decide merupakan tahap untuk memilih rancangan terbaik dari ide yang dihasilkan pada tahap diverge. Adapun cara untuk memilih ide rancangan terbaik adalah dengan mengevaluasi ide berdasarkan usability heuristic [10] dan petunjuk dari platform Messenger. Didukung pula dengan beberapa rujukan mengenai bagaimana bahasa yang perlu digunakan oleh chatbot [6].

Pola desain antarmuka ketika mengatasi masukan berupa teks dalam aktivitas menghapus reminder juga digunakan pada aktivitas menjadwal ulang, menunda, dan menandai selesai pada reminder. Ketika pengguna mengirimkan teks yang berisi kata kunci menghapus, chatbot akan memunculkan reminder yang dimaksud jika reminder berhasil ditemukan. Di samping itu, tombol yang dimunculkan berfokus pada tujuan aktivitas, yaitu menampilkan tombol "Remove" untuk aktivitas menghapus. Pada Lampiran Gambar II diperlihatkan desain antarmuka aktivitas menghapus reminder.

\section{Tahap 5 - Prototype}

Prototype merupakan tahap untuk melakukan implementasi rancangan ke dalam bentuk prototype dari ide terbaik yang telah dipilih pada tahap decide. Prototype yang dihasilkan pada tahap ini berupa high-fidelity prototype agar dapat digunakan dalam berinte-raksi dengan pengguna [11].

\section{Tahap 6 - Validate}

Pokok utama pada tahap validate yaitu dilakukan pengujian terhadap prototype chatbot baru yang telah diimplementasikan. Pengujian dilakukan untuk mencari tahu apakah rancangan chatbot baru ber- 


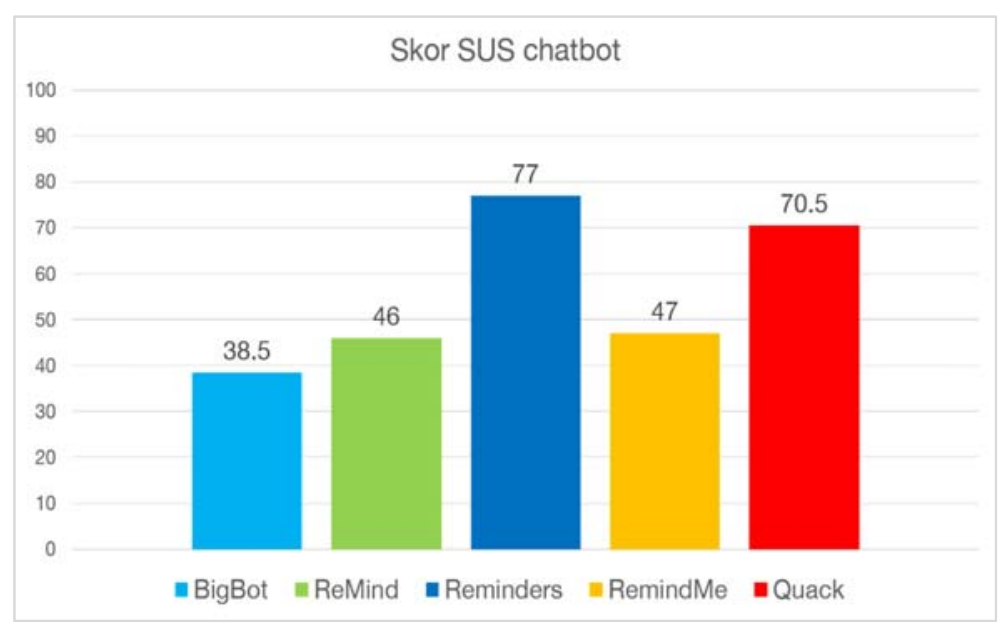

Gambar 4. Skor SUS Chatbot

hasil meningkatkan pengalaman pengguna atau tidak. Pengumpulan data mengikuti metode usability testing yang digunakan pada tahap understand.

Kompenen usability testing yang digunakan kali ini masih menggunakan skenario dan kuesioner pendapat serta saran yang sama dengan tahap understand, tetapi memiliki partisipan yang berbeda sehingga feedback yang diterima tidak terganggu dengan hasil chatbot lama.

\section{Hasil dan Pembahasan}

Pengujian dilakukan untuk mencari tahu apakah rancangan chatbot baru berhasil meningkatkan pengalaman pengguna atau tidak. Pengumpulan data mengikuti metode usability testing yang digunakan pada tahap understand. Komponen usability testing yang digunakan kali ini masih menggunakan skenario dan kuesioner pendapat serta saran yang sama dengan tahap understand, tetapi memiliki partisipan yang berbeda sehingga feedback yang diterima tidak terganggu dengan hasil chatbot lama.

\section{Kesuksesan dan Durasi Pengerjaan Skenario}

Pada bagian ini dijelaskan mengenai perbandingan kesuksesan dan durasi pengerjaan skenario chatbot lama dan baru. Kesuksesan pengerjaan skenario dibagi menjadi tiga kriteria, antara lain: 1) Sukses jika partisipan dapat menjalankan skenario sesuai dengan yang ditetapkan oleh penulis pada masingmasing chatbot per skenario tanpa hambatan yang ditandai dengan warna hijau; 2) Sukses namun kesulitan jika partisipan berhasil menjalankan skenario namun mengalami hambatan yang ditandai dengan warna kuning; 3) Gagal jika partisipan tidak berhasil ditandai dengan warna merah.

Adapun sel pada tabel yang ditandai dengan tanda minus (-) berarti skenario yang ada tidak dikerjakan oleh partisipan. Hal tersebut dapat disebabkan oleh skenario yang gagal sebelumnya sehingga skenario selanjutnya tidak dapat dikerjakan atau chatbot mengalami masalah saat usability testing berlangsung. Ringkasan data kesuksesan dan durasi pengerjaan skenario ditampilkan pada Lampiran Tabel IV. Satuan durasi pada tabel disajikan dalam detik. Identitas partisipan dilambangkan dengan P1, P2, hingga P25.

Hasil usability testing memperlihatkan bahwa tingkat kesuksesan pada chatbot baru bernama Quack mengalami peningkatan dibandingan dengan chatbot lama. Dengan membandingkan total 50 pengerjaan skenario pada masing-masing chatbot memperlihatkan tingkat kesuksesan skenario chatbot baru sebesar 78\% sukses dikerjakan, sebesar $4 \%$ sukses namun kesulitan, dan sebesar $18 \%$ gagal dikerjakan. Kesuksesan tersebut naik 32,5\% dibandingkan dengan rata-rata skenario yang berhasil pada chatbot lama. Perolehan tersebut diperlihatkan pada Lampiran Tabel V.

Persentase keberhasilan yang lebih tinggi pada chatbot baru merupakan pengaruh dari hasil analisis dan rancangan use case diagram, activity diagram, serta desain antarmuka dari usability testing chatbot lama. Selain itu, rancangan interaksi berpengaruh pada aktivitas yang menjadi sorotan permasalahan yaitu menambah, melihat daftar, dan menghapus reminder.

Fenomena yang ditemukan adalah pada skenario gagal dengan durasi lama dan singkat, sukses kesulitan dengan durasi lama, dan skenario berhasil dengan durasi lama. Skenario yang terdapat pada tabel dipilih berdasarkan durasi yang memiliki perbedaan signifikan dibandingkan pada chatbot yang sama. Ditemukan bahwa pengalaman dan tingkat frustasi partisipan serta tingkat kemampuan chat- 


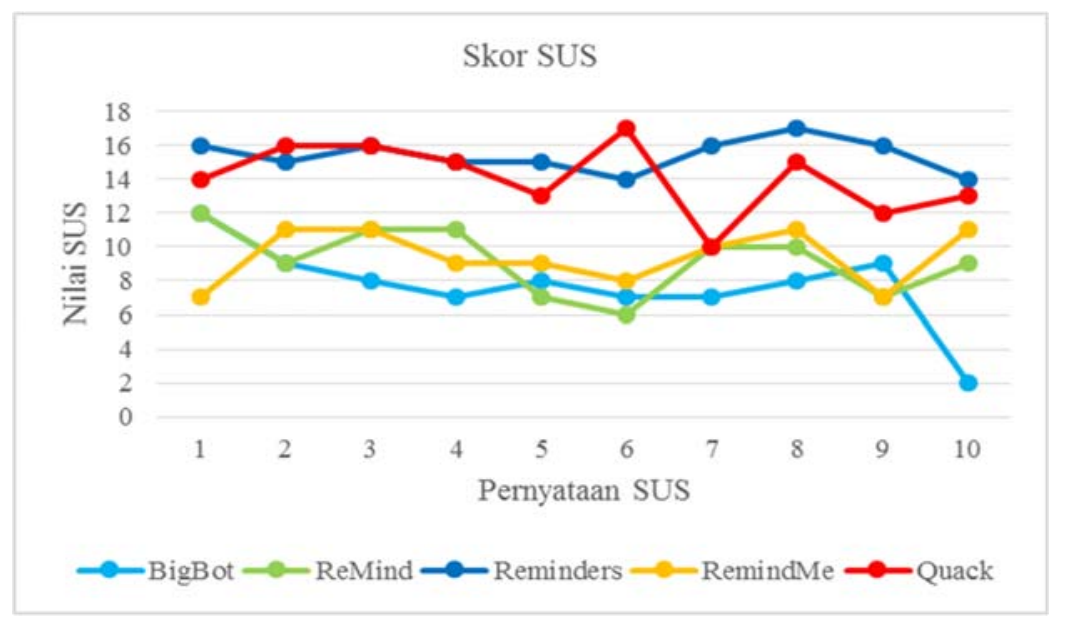

Gambar 5. Perincian Skor SUS

bot menjadi faktor durasi dan kesuksesan yang bervariasi. Detil dari fenomena yang ditemukan digambarkan pada Lampiran Tabel VI.

\section{Skor SUS}

Untuk memperoleh skor SUS yang dapat dijadikan acuan, perlu dilakukan perhitungan sesuai dengan rumusan yang ada. Skor akhir SUS mempunyai rentang nilai $0-100$, sedangkan nilai setiap pernyataan mempunyai rentang nilai $0-4$. Skor diolah dengan menghitung nilai pada pernyataan dengan urutan angka ganjil dengan $\left(x_{i}-1\right)$, sedangkan urutan angka genap dengan $\left(5-x_{i}\right)$. Kemudian skor dari setiap pernyataan dijumlahkan dan mengalikan hasil jumlahan dengan 2,5 untuk mendapatkan nilai tertinggi 100 . Seperti yang tergambar pada persamaan(1) dimana $U_{i}$ mengacu kepada nilai pernyataan ke-i yang bertambah mulai dari satu hingga lima. Dimana $\mathrm{n}$ berarti banyaknya pernyataan [12].

$$
S U S=2,5 \times\left[\sum_{n=1}^{5}\left(U_{2 n-1}-1\right)+\left(5-U_{2 n}\right)\right]
$$

Pengisian kuesioner SUS dilakukan setelah partisipan menjalankan skenario yang diberikan. Melihat hubungan kesuksesan pengerjaan skenario setiap partisipan dengan skor SUS ditemukan bahwa sebanyak $36 \%$ partisipan yang memiliki persentase kesuksesan yang rendah cenderung memberikan skor SUS yang rendah (rata-rata persentase kesuksesan $=51,6 \%$ dan rata-rata skor SUS $=$ 55,8). Persentase keberhasilan partisipan dihitung dari total sepuluh skenario yang dijalankan masing-masing partisipan. Hubungan antara persentase kesuksesan dan skor SUS yang diberikan digambarkan pada Gambar 3. Aksis X pada gambar merupakan identitas partisipan, sedangkan aksis $\mathrm{Y}$ merupakan persentase kesuksesan dan representasi dari skor akhir SUS.

Nilai yang ditampilkan pada Gambar 4 adalah nilai rata-rata dari skor SUS masing-masing chatbot. Dapat dilihat bahwa skor SUS chatbot baru mengalami peningkatan dari tiga chatbot lama yaitu BigBot, ReMind, dan RemindMe, sedangkan masih lebih kecil dibandingkan dengan skor SUS Reminders. Hal tersebut disebabkan oleh chatbot baru yang masih berbentuk prototype, padahal chatbot baru lebih unggul secara rancangan dan tanggapan dari partisipan. Akan tetapi, partisipan lebih mudah berinteraksi dengan data yang sebenarnya sehingga beberapa partisipan merasa kebingungan saat melihat daftar ataupun keterangan waktu reminder pada chatbot baru, dimana data yang sebenarnya tidak diterapkan pada prototype sebagai batasan masalah.

Peningkatan skor SUS pada chatbot baru dapat dilihat pada Gambar 5 yang merupakan gambaran nilai SUS setiap pernyataan masing-masing chatbot setelah diolah dari hasil penilaian SUS. Aksis X pada gambar merupakan pernyataan SUS, sedangkan aksis Y merupakan nilai SUS yang telah diolah sesuai dengan urutan pernyataan. Dapat dilihat pada gambar bahwa skor SUS chatbot baru dipengaruhi oleh perubahan nilai SUS pada pernyataan 2 dan 6. Sesuai dengan Lampiran Tabel I, isi dari pernyataan 2 dan 6 adalah "Banyak hal kompleks yang tidak diperlukan pada chatbot ini” dan "Banyak hal yang tidak konsisten dari chatbot ini". Dari nilai yang tinggi pada dua pernyataan tersebut dapat disimpulkan bahwa rancangan chatbot baru dirasa efektif oleh partisipan.

\section{Perbandingan Skenario}

Pada bagian ini akan dibahas mengenai perbandingan tanggapan partisipan pada chatbot yang dipe- 
TABEL 2

\begin{tabular}{|c|c|c|c|c|c|c|c|}
\hline & & 11 & $N J_{A}$ & & & & \\
\hline \multirow[t]{2}{*}{$\begin{array}{l}\text { Nama } \\
\text { Chatbot }\end{array}$} & \multicolumn{3}{|c|}{ Langkah ke- } & \multicolumn{3}{|c|}{$\begin{array}{c}\text { Persentase } \\
\text { Kesuksesan } \\
(\%)\end{array}$} & \multirow[t]{2}{*}{$\begin{array}{l}\text { Durasi } \\
\text { (detik) }\end{array}$} \\
\hline & Best & Avg. & Worst & $\mathrm{S}$ & $\mathrm{SK}$ & $\mathrm{G}$ & \\
\hline BigBot & 1 & 1 & 2 & 60 & 0 & 40 & 25 \\
\hline ReMind & 2 & 2 & 3 & 40 & 40 & 20 & 57,8 \\
\hline Reminders & 2 & 3 & 5 & 40 & 40 & 20 & 41,4 \\
\hline RemindMe & 2 & 3 & 5 & 40 & 40 & 20 & 44,8 \\
\hline Quack & 2 & 2 & 2 & 100 & 0 & 0 & 28,4 \\
\hline
\end{tabular}

Keterangan:

Avg. = Rata-rata, $\mathrm{S}=$ Sukses, $\mathrm{SK}=$ Sukses tetapi kesulitan, dan $\mathrm{G}=$ Gagal.

roleh saat melakukan usability testing. Namun, dikarenakan keterbatasan jumlah halaman maka akan dijelaskan perbandingan skenario enam sebagai contoh.

Pada skenario enam partisipan diminta untuk menghapus reminder yang telah ditambahkan pada skenario empat. Hasil dari 20 skenario yang dikerjakan pada usability testing chatbot lama, ditemukan sebanyak $40 \%$ partisipan mencoba menghapus reminder menggunakan teks, tetapi saat usability testing hanya satu partisipan yang menggunakan teks pada chatbot baru. Interaksi partisipan yang berbeda menghasilkan variasi kesuksesan skenario ini yang diperlihatkan pada Tabel 2. Kesuksesan chatbot baru yang mencapai 100\% dipengaruhi oleh antarmuka pada tombol dan daftar reminder.

Chatbot BigBot dapat menangani aktivitas menghapus reminder menggunakan teks, tetapi judul reminder yang ingin dihapus oleh partisipan haruslah sama dengan reminder yang ada atau sesuai dengan nomor urut reminder pada daftar reminder. Hal tersebut menyulitkan partisipan yang tidak hafal dengan nama ataupun nomor urut reminder. Di sisi lain, RemindMe hanya menyediakan pilihan dengan label "Mark as done" dan "Change time" pada daftar reminder dan tidak terdapat label dengan arti menghapus. RemindMe menganggap "Mark as done" juga termasuk menghapus karena secara teknis meniadakan reminder dari daftar. Namun, tidak semua partisipan mengetahui hal tersebut dan menyulitkan dalam menghapus reminder.

Pada BigBot, reminder yang dihapus tidak mendapatkan konfirmasi sehingga partisipan tidak dapat mencegah jika salah menghapus reminder. Di samping itu, ReMind akan melakukan konfirmasi ketika menghapus reminder untuk menghindari partisipan melakukan kesalahan. Pada Lampiran Gambar III digambarkan interaksi dalam skenario enam.

\section{Kesimpulan}

Berdasarkan penelitian yang telah dilakukan, dapat ditarik kesimpulan bahwa tingkat kesuksesan pada chatbot baru lebih tinggi 32,5\% dibandingkan dengan chatbot lama secara rata-rata. Skor SUS chatbot baru sebanyak 32 lebih unggul dari BigBot, sebanyak 24,5 lebih unggul dari ReMind, dan sebanyak 23,5 lebih unggul dari RemindMe. Namun, masih kalah sebanyak 6,5 dengan Reminders. Secara rata-rata skor SUS chatbot baru meningkat sebanyak 18,4 dibandingkan chatbot lama. Hal tersebut memberikan gambaran bahwa pendekatan user-centered design baik digunakan untuk menganalisis permasalahan pada produk yang berhubungan langsung dengan pengguna. Serta pemilihan antarmuka yang tepat dapat meningkatkan user experience chatbot yang menggunakan antarmuka.

Saran yang dapat diberikan untuk penelitian selanjutnya adalah penambahan jumlah partisipan dalam usability testing. Selain itu pengujian usability testing selanjutnya dapat menggunakan chatbot yang sudah jadi, bukan prototype. Serta penggunaan pustaka untuk membaca keterangan tanggal dan waktu di dalam pesan dan basis data sebagai penyimpanan reminder yang ditambahkan.

\section{Referensi}

[1] Tillotson, K. D., "Implementation, Analysis, and Evaluation of A Humanized Information Retrieval ChatBot," Tesis, The Faculty of The Computer Science Department, Southern University and A\&M College, Johor, 2012.

[2] Shawar, B. A. and Atwell, E., "Chatbot: are they really useful?", LDV-Forum 2007, vol. 22, no. 1, pp. 29-49, 2007.

[3] Allen, D., "Getting things done: the art of stress-free productivity," New York: Penguin Books, 2015.

[4] Kuligowska, K., "Commercial chatbot: performance evaluation, usability metrics and quality standards of embodied conversational agents," Professionals Center for Business Research, vol. 2, no. 0202.22, pp. 1-16, 2015.

[5] Abras, C., et al., "User-centered design", Bainbridge, W. Encyclopedia of Human-Computer Interaction. Thousand Oaks: Sage Publications, vol. 37, no. 4, pp. 445-446, 2004.

[6] Hill, J., et al., "Real conversations with artificial intelligence: a comparison between human-human online conversations and humanchatbot conversations", Computers in Human Behavior, vol. 49, pp. 245-250, 2015.

[7] Hung, V., et al., "Towards a method for evaluating naturalness in conversational dialog systems", IEEE International Conference of Systems, Man, and Cybernetics, San Antonio, pp. 1236-1241, 2009.

[8] Knapp, J., et al., "Sprint: how to solve big problems and test new ideas in just five days", New York: Simon \& Schuster, Inc., 2016. 
[9] Sauro, J., "A practical guide to the system usability scale", Measuring Usability LLC, Denver, 2011.

[10] Nielsen, J., and Molich, R., "Heuristic evaluation of user interfaces", Proc. ACM CHI '90 Conf. Seattle, WA, pp. 249-256, 1990.

[11] Walker, M., Takayama, L., and Landay, J. A., "High-fidelity or low-fidelity, paper or computer? Choosing attributes when testing web prototypes," in Proceedings of the human factors and ergonomics society annual meeting, vol. 46, no. 5, pp. 661-665, 2002.

[12] Harrati, N., et al., "Exploring user satisfaction for e-learning systems via usage-based metrics and system usability scale analysis", $\mathrm{Co}-$ mputers in Human Behavior, vol. 61, pp. 463471, 2016.

\section{Lampiran}

LAMPIRAN TABEL I

\begin{tabular}{lll} 
& \multicolumn{2}{c}{ DAFTAR CHATBOT LAMA } \\
\hline Nama Chatbot & \multicolumn{1}{c}{ ID Akun } & \multicolumn{1}{c}{ Halaman Facebook } \\
\hline BigBot & @myBigBot & https://facebook.com/myBigBot/ \\
ReMind & @mindnodes.remind & https://facebook.com/mindnodes.remind/ \\
Reminders & @remindersyellow & https://facebook.com/remindersyellow/ \\
RemindMe & @ botremindme & https://facebook.com/botremindme/ \\
\hline
\end{tabular}

LAMPIRAN TABEL II

KUISIONER SUS (SYSTEM USABILITY SCALE)

\begin{tabular}{|c|c|c|c|c|c|c|}
\hline No & Kuisioner SUS & \multicolumn{5}{|c|}{ Nilai SUS } \\
\hline 1. & Saya tertarik untuk sering meng-gunakan chatbot ini. & 1 & 2 & 3 & 4 & $\overline{5}$ \\
\hline 2. & Banyak hal kompleks yang tidak diperlukan pada chatbot ini. & 1 & 2 & 3 & 4 & 5 \\
\hline 3. & Chatbot ini mudah untuk diguna-kan. & 1 & 2 & 3 & 4 & 5 \\
\hline 4. & Saya membutuhkan bantuan dari orang lain ketika menggunakan chatbot ini. & 1 & 2 & 3 & 4 & 5 \\
\hline 5. & Fitur-fitur dari chatbot ini berja-lan dengan baik. & 1 & 2 & 3 & 4 & 5 \\
\hline 6. & Banyak hal yang tidak konsisten dari chatbot ini. & 1 & 2 & 3 & 4 & 5 \\
\hline 7. & Menurut saya, chatbot ini akan mu-dah digunakan oleh banyak orang. & 1 & 2 & 3 & 4 & 5 \\
\hline 8. & Saya menemukan chatbot ini su-lit untuk digunakan. & 1 & 2 & 3 & 4 & 5 \\
\hline 9. & Saya merasa nyaman mengguna-kan chatbot ini. & 1 & 2 & 3 & 4 & 5 \\
\hline 10. & Saya perlu mempelajari banyak hal sebelum menggunakan chatbot ini. & 1 & 2 & 3 & 4 & 5 \\
\hline
\end{tabular}

LAMPIRAN TABEL III

SKENARIO USABILITY TESTINC

\begin{tabular}{|c|c|c|}
\hline No & Tujuan Aktivitas & Deskripsi Skenario \\
\hline 1. & $\begin{array}{l}\text { Menambah reminder } \\
\text { dengan waktu tertentu }\end{array}$ & $\begin{array}{l}\text { "Teman kerjamu memberitahu bahwa besok kamu memiliki jadwal meeting jam } 8 \text { pagi. } \\
\text { Gunakanlah chatbot untuk mengingatkanmu tentang jadwal meeting tersebut." }\end{array}$ \\
\hline 2. & $\begin{array}{l}\text { Menambah reminder } \\
\text { dengan durasi tertentu }\end{array}$ & $\begin{array}{l}\text { "Andi memintamu untuk meneleponnya dalam lima menit lagi. Agar tidak lupa, kamu } \\
\text { menggunakan chatbot untuk mengingatkanmu." }\end{array}$ \\
\hline 3. & $\begin{array}{l}\text { Melihat daftar remin- } \\
\text { der }\end{array}$ & $\begin{array}{l}\text { "Budi mengajakmu jogging di hari <..> pagi. Sebelum kamu menyetujuinya, kamu perlu } \\
\text { memastikan apakah kamu punya kegiatan lain atau tidak di hari <...> pagi tersebut. } \\
\text { Periksalah chatbotmu untuk memastikannya." }\end{array}$ \\
\hline 4. & $\begin{array}{l}\text { Menambah reminder } \\
\text { dengan nama hari }\end{array}$ & $\begin{array}{l}\text { "Ternyata kamu tidak mempunyai kegiatan di hari }<\ldots>\text { pagi. Agar tidak lupa, kamu } \\
\text { menggunakan chatbot untuk mengingatkanmu tentang jogging di }<\ldots>\text { pagi bersama Budi." }\end{array}$ \\
\hline 5. & $\begin{array}{l}\text { Menunda reminder de- } \\
\text { ngan durasi tertentu }\end{array}$ & $\begin{array}{l}\text { "Sudah lima menit berlalu, kamu diingatkan oleh chatbot untuk menelepon Andi. Ternyata, } \\
\text { Andi belum siap untuk ditelepon, lalu dia meminta untuk menundanya dua menit lagi. } \\
\text { Sekarang, tundalah reminder tersebut selama dua menit." }\end{array}$ \\
\hline 6. & reminder & $\begin{array}{l}\text { "Sekarang sudah hari }<\ldots>\text {, tiba-tiba Budi memberitahu bahwa dia sedang sakit dan tidak } \\
\text { bisa jogging esok hari. Mengetahui hal tersebut, kamu membatalkan kegiatan jogging di } \\
\text { remindermu." }\end{array}$ \\
\hline 7. & $\begin{array}{l}\text { Menandai selesai pada } \\
\text { reminder }\end{array}$ & $\begin{array}{l}\text { "Bayangkan sekarang kamu sudah menelepon Andi, kemudian kamu memberi tanda selesai } \\
\text { pada reminder tersebut." }\end{array}$ \\
\hline 8. & $\begin{array}{l}\text { Menambah reminder } \\
\text { dengan tanggal terten- } \\
\text { tu }\end{array}$ & $\begin{array}{l}\text { "Dosen pembimbingmu ingin bertemu denganmu pada tanggal }<\ldots>\text {, agar tidak lupa, kamu } \\
\text { menggunakan chatbot untuk mengingatkanmu." }\end{array}$ \\
\hline 9. & $\begin{array}{l}\text { Menjadwal ulang remi- } \\
\text { nder }\end{array}$ & $\begin{array}{l}\text { "Ternyata keesokan harinya, dosen pembimbingmu ingin mengganti tanggal pertemuan itu } \\
\text { menjadi tanggal }\langle\ldots . .>\text {, lalu kamu mengubah tanggal reminder tersebut." }\end{array}$ \\
\hline 10. & $\begin{array}{l}\text { Menambah dua remin- } \\
\text { der }\end{array}$ & $\begin{array}{l}\text { "Kamu ingin diingatkan untuk mengerjakan tugas jam } 7 \text { malam. Setelah itu, kamu ingin } \\
\text { diingatkan untuk minum obat jam } 9 \text { malam. Gunakanlah chatbot untuk mengingatkanmu." }\end{array}$ \\
\hline
\end{tabular}


LAMPIRAN TABEL IV

Perbandingan Persentase Kesuksesan PengerjaAn Skenario Antara Chatbot lama dan Baru

\begin{tabular}{lcccccc}
\hline \multirow{2}{*}{ Nama Chatbot Lama } & \multicolumn{3}{c}{ Persentase (\%) } & \multicolumn{2}{c}{ Persentase Perbandingan Dengan Chatbot Baru (\%) } \\
\cline { 2 - 7 } & S & SK & G & S & SK & -14 \\
BigBot & 18 & 18 & 64 & +60 & -12 & -46 \\
ReMind & 56 & 16 & 28 & +22 & -8 & -10 \\
Reminders & 68 & 12 & 20 & +10 & -26 & -12 \\
RemindMe & 40 & 30 & 30 & +38 & -15 & $-17,5$ \\
\hline Rata-rata & 45,5 & 19 & 35,5 & $+32,5$ & \\
\hline
\end{tabular}

Keterangan:

$\mathrm{S}=$ Sukses, $\mathrm{SK}=$ Sukses tetapi kesulitan, dan $\mathrm{G}=$ Gagal .

LAMPIRAN TABEL V

FENOMENA PENGERJAAN SKENARIO

\begin{tabular}{|c|c|c|}
\hline Fenomena & Terjadi Pada & Detil \\
\hline \multirow{15}{*}{$\begin{array}{l}\text { Gagal } \\
\text { dengan } \\
\text { durasi lama }\end{array}$} & Skenario 1 & Skenario yang dikerjakan berlangsung selama 318 detik. \\
\hline & $\begin{array}{l}\text { Chatbot } \\
\text { BigBot } \\
\text { Partisipan P1 }\end{array}$ & $\begin{array}{l}\text { b. Partisipan mengalami durasi pengerjaan yang lebih lama disebabkan oleh chatbot } \\
\text { yang tidak memahami format waktu yang dituliskan oleh partisipan, seperti " } 8 \\
\text { o'clock", dimana kejadian ini berlangsung selama } 110 \text { detik. }\end{array}$ \\
\hline & & $\begin{array}{l}\text { c. Partisipan mencoba hingga dua kali untuk mengubah waktu reminder karena chatbot } \\
\text { salah dalam memahami keterangan waktu yang diberikan, dimana kejadian ini } \\
\text { berlangsung selama } 94 \text { detik. }\end{array}$ \\
\hline & & $\begin{array}{l}\text { Kejadian tersebut membuat partisipan frustasi hingga memilih untuk tidak } \\
\text { melanjutkan skenario. }\end{array}$ \\
\hline & Skenario 2 & Skenario yang dikerjakan berlangsung selama 127 detik. \\
\hline & $\begin{array}{l}\text { Chatbot } \\
\text { BigBot }\end{array}$ & $\begin{array}{l}\text { b. Partisipan menghabiskan waktu selama } 62 \text { detik mencoba memahami pesan yang } \\
\text { diberikan oleh chatbot saat menanyakan waktu yang diinginkan. }\end{array}$ \\
\hline & Partisipan P5 & $\begin{array}{l}\text { Partisipan gagal menyelesaikan skenario disebabkan waktu yang dicantumkan tidak } \\
\text { sesuai dengan skenario yang diminta. }\end{array}$ \\
\hline & Sken & Skenario yang dikerjakan berlangsung selama 194 detik. \\
\hline & $\begin{array}{l}\text { Chatbot } \\
\text { Reminders }\end{array}$ & $\begin{array}{l}\text { b. Partisipan menghabiskan waktu selama } 105 \text { detik dikarenakan salah memahami pesan } \\
\text { yang dikirimkan oleh chatbot }\end{array}$ \\
\hline & Parti & $\begin{array}{l}\text { Partisipan menganggap chatbot menanyakan waktu reminder yang ingin dimunculkan } \\
\text { oleh partisipan, sedangkan chatbot sebenarnya menanyakan waktu untuk } \\
\text { menambahkan reminder. }\end{array}$ \\
\hline & Sken & Skenario yang dikerjakan berlangsung selama 238 detik. \\
\hline & Chatbot & b. Partisipan mengharapkan chatbot langsung menambahkan reminder ketika \\
\hline & RemindMe & keterangan waktu dicantumkan di awal kalimat, tetapi chatbot tidak membaca \\
\hline & Partisipan P18 & keterangan waktu di awal kalimat. Kejadian ini berlangsung selama 56 detik. \\
\hline & & $\begin{array}{l}\text { Partisipan menghabiskan waktu selama } 74 \text { detik untuk memahami format waktu yang } \\
\text { diminta oleh chatbot. }\end{array}$ \\
\hline \multirow{6}{*}{$\begin{array}{l}\text { Gagal } \\
\text { dengan } \\
\text { durasi } \\
\text { singkat }\end{array}$} & Sker & Skenario yang dikerjakan berlangsung selama 7 detik. \\
\hline & Chatbot & Partisipan menambahkan reminder dengan judul yang tidak sesuai dengan skenario, \\
\hline & RemindMe & an tetapi partisipan tidak menyadari hal tersebut. \\
\hline & Skenario 7 & Ske \\
\hline & $\begin{array}{l}\text { Chatbot } \\
\text { ReMind }\end{array}$ & $\begin{array}{l}\text { Partisipan menunda reminder menggunakan teks, dimana chatbot hanya membalas } \\
\text { dengan "OK!". }\end{array}$ \\
\hline & Partisipan P6 & Partisipan menganggap reminder berhasil ditunda. \\
\hline \multirow{4}{*}{$\begin{array}{l}\text { Sukses } \\
\text { tetapi } \\
\text { kesulitan } \\
\text { dengan } \\
\text { durasi lama }\end{array}$} & Skenario 8 & Skenario yang dikerjakan berlangsung selama 295 detik. \\
\hline & Chatbot & Partisipan menghabiskan waktu selama 229 detik untuk menambahkan reminder, \\
\hline & RemindMe & tetapi format yang dimasukkan tidak dimengerti oleh chatbot. \\
\hline & Partisipan P19 & \\
\hline \multirow{4}{*}{$\begin{array}{l}\text { Sukses } \\
\text { dengan } \\
\text { durasi lama }\end{array}$} & Skenario 2 & Skenario yang dikerjakan berlangsung selama 71 detik. \\
\hline & Chatbot & Partisipan menghabiskan waktu selama 53 detik untuk memilih kata yang kalimat \\
\hline & BigBot & untuk meminta chatbot menambahkan reminder. Seperti menggunakan kata "in" \\
\hline & Partisipan P3 & \\
\hline
\end{tabular}


88 Jurnal Sistem Informasi (Journal of Information System), Volume 13, Issue 2, October 2017
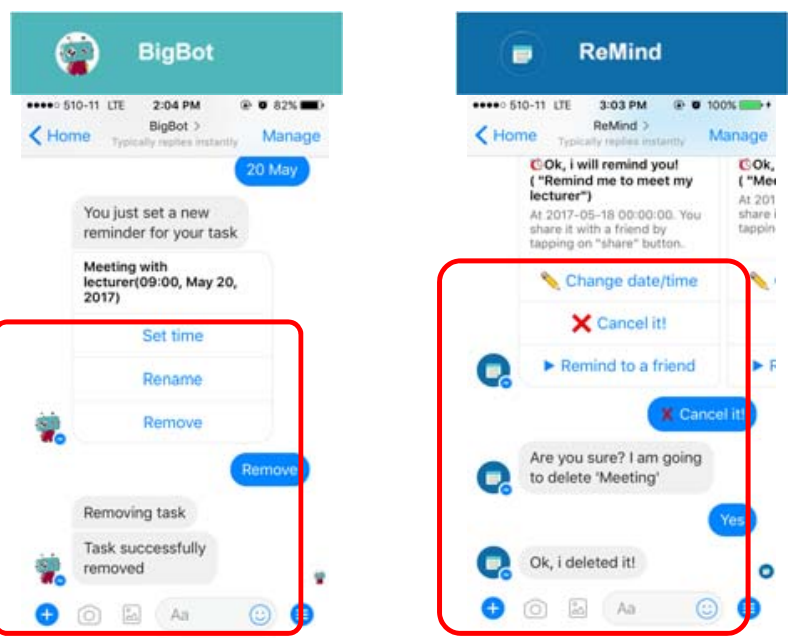

Lampiran Gambar I. Antarmuka BigBot dan ReMind ketika menghapus reminder
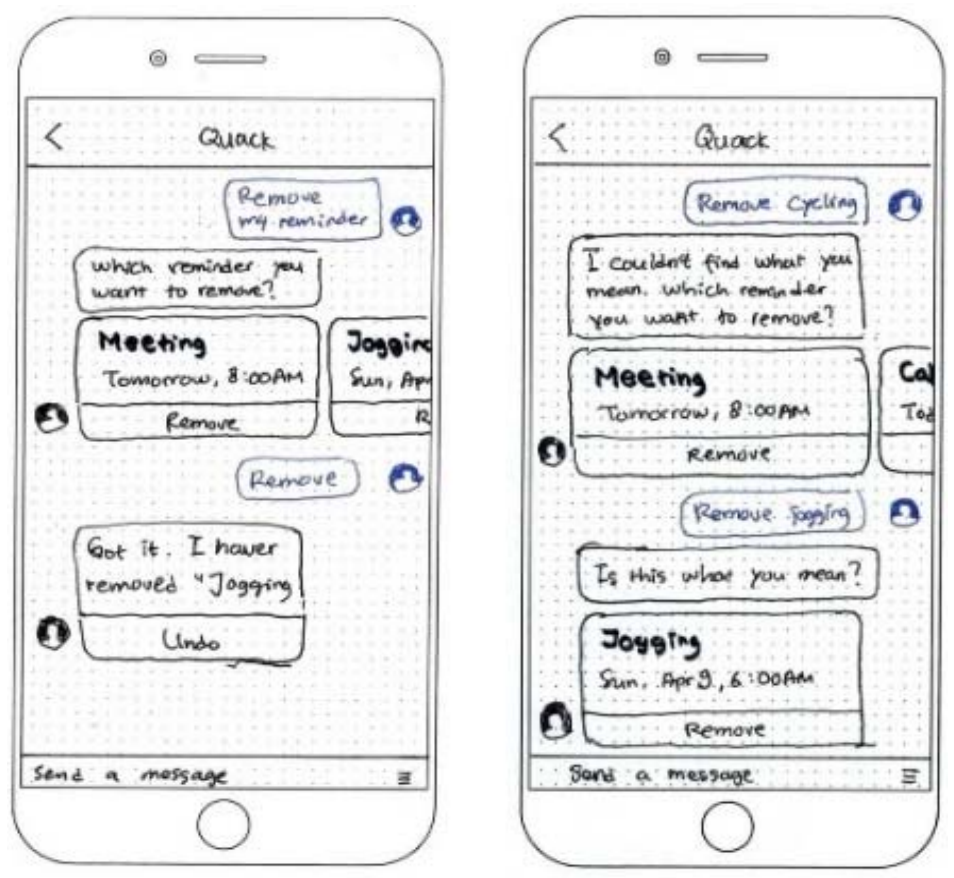

Lampiran Gambar II. Antarmuka menghapus reminder 


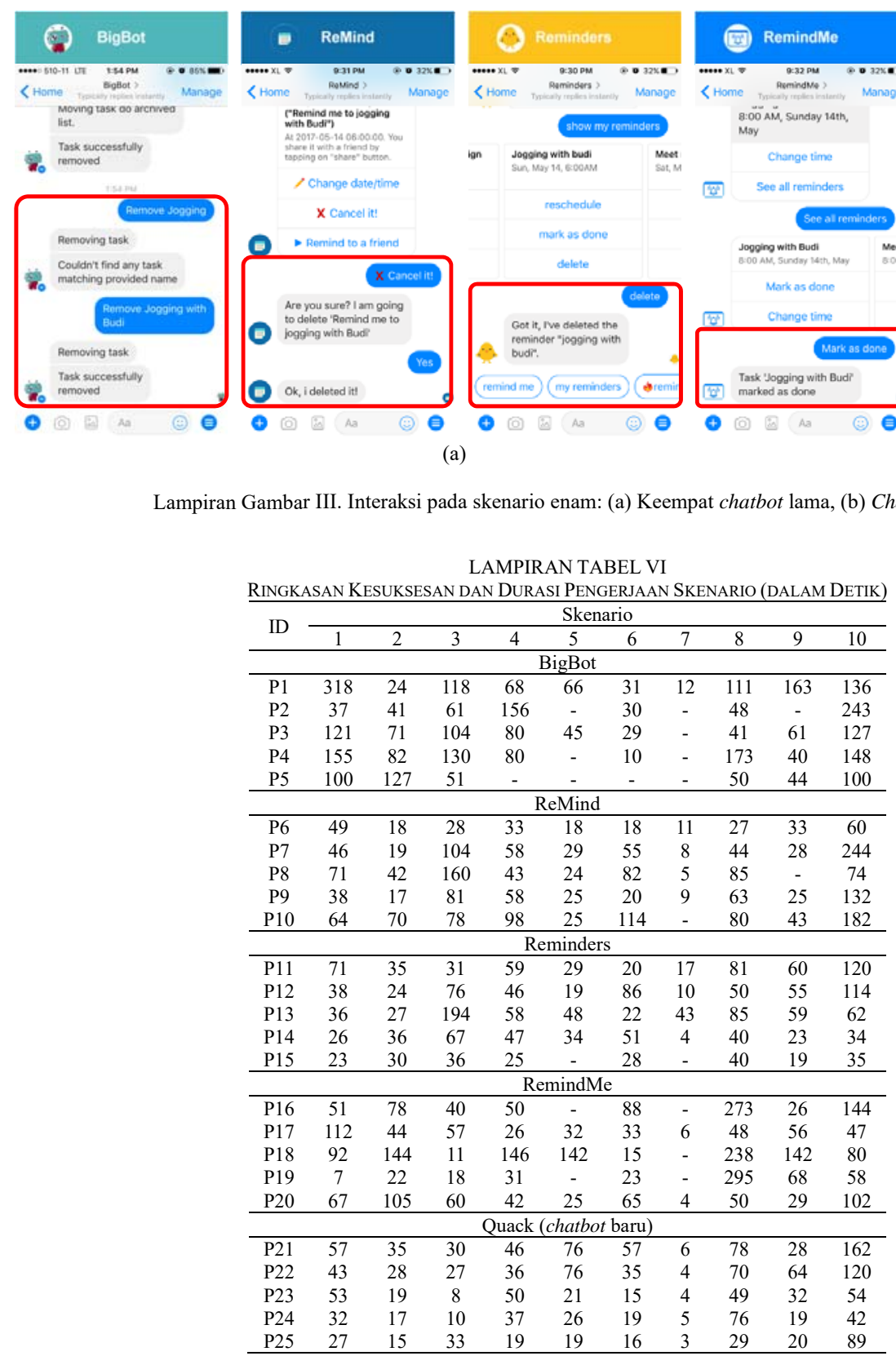

